\title{
Prevalence of CMV infection among sexually active adolescents: a matched case-control study
}

This article was published in the following Dove Press journal:

Adolescent Health, Medicine and Therapeutics

29 April 2014

Number of times this article has been viewed

\section{Michael K Foxworth II Isca R Wilms \\ Richard R Brookman \\ Stephanie Crewe \\ Stuart P Adler}

Department of Pediatrics and Microbiology, Virginia Commonwealth University, Richmond, VA, USA
Correspondence: Stuart P Adler Department of Pediatrics and Microbiology, Virginia Commonwealth University, I I0I East Marshall Street, Richmond, VA 23298, USA

Email sadler@vcu.edu
Background: We observed previously that African American adolescents in Richmond reporting infrequent sexual activity had cytomegalovirus (CMV) seroprevalence rates one half that of their adult mothers and caregivers. We therefore sought to determine if sexually active African American adolescents have higher rates of CMV infection than sexually inactive African American adolescents.

Methods: Cases (aged 13-18 years) sought care for a sexually transmitted infection (STI) or pregnancy. Controls were sexually inactive and matched to cases for age, race, and gender and enrolled at the same clinic as cases and sought medical treatment unrelated to an STI. Subjects completed a questionnaire, provided saliva for antibody testing, and were interviewed for determination of sexual activity.

Results: Two groups of sexually active cases were enrolled. The first group had a diagnosis of an STI. In this group, both cases and matched controls were seropositive at a rate of $32 \%$ (7/22 for cases and 7/22 for controls). In the second group, cases self-reported an STI but objective evidence was lacking. In this group, cases were seropositive at a rate of $38 \%$ (six of 16) compared with matched controls among whom $6.3 \%$ were seropositive (one in 16). The overall rate of seropositivity in all 38 cases was $34 \%$ compared with a rate of $21 \%$ for all controls ( $P=0.3$, odds ratio $2.0,95 \%$ confidence interval $0.6-7.5$ ).

Conclusion: Our results confirm lower rates of CMV infection among the current generation of African American adolescents compared with African American adults in Richmond, and suggest that this is not associated with sexual activity.

Keywords: cytomegalovirus, sexually transmitted disease, adolescents, African Americans, seroprevalence

\section{Introduction}

Many studies report that African Americans have nearly twice the prevalence of cytomegalovirus (CMV) infection than that in age-matched and gender-matched Caucasians. ${ }^{1-11}$ For example, a study of 1,898 pregnant women in Texas found race to be independently correlated with an increased rate of seropositivity. ${ }^{9}$ Among African Americans, $74.4 \%$ were seropositive for CMV compared with 46.3\% for other races. Similarly, in Seattle, WA, USA, race was an independent risk factor for CMV seropositivity among women tested at a sexually transmitted disease clinic. ${ }^{3}$ Seropositivity ranged between $80 \%$ and $100 \%$, depending on the number of sexual partners. For teenage girls attending a contraceptive clinic, race was an independent risk factor for CMV seropositivity, with $89 \%$ of African Americans testing seropositive for $\mathrm{CMV}^{6}$ Another study reported that $86 \%$ of urban African American girls of mean 
age 14.5 (12-16) years were seropositive for CMV. ${ }^{5}$ This was significantly higher than findings observed among Caucasian girls of similar ages from the same city. These findings have also been confirmed in two large US population-based studies from 1988 to 2004 where African Americans compared with Caucasians had higher seroprevalence rates at all ages. ${ }^{10,11}$

We have also observed a high rate (80\%) of CMV infections among African American adults in Richmond, VA, USA. ${ }^{7,12}$ However, in Richmond, we unexpectedly observed that African American children and adolescents had CMV seroprevalence rates one half that of their adult mothers and caregivers. The adolescents we observed reported infrequent sexual activity. ${ }^{12}$ Of the 62 adolescents enrolled, six reported sexual activity, each with only one sexual partner, and all reported consistently using condoms. Based on this observation, we hypothesized that the greater than $50 \%$ decrease in the prevalence of CMV infection among the current generation of African American children and adolescents as compared with African American adults may be due to decreased sexual activity, increased condom use, or a reduced number of sexual partners during adolescence. ${ }^{12} \mathrm{We}$ therefore performed a matched case-control study to test the hypothesis that sexually active African American adolescents have higher rates of CMV infection than sexually inactive African American adolescents.

\section{Materials and methods}

The study was approved by the Virginia Commonwealth University institutional review board. A waiver of consent was used for subjects aged 15-17 years who were unaccompanied, seeking medical care associated with sexually transmitted infections (STIs), or withholding permission to contact their parent or legal guardian. A waiver of documentation of consent was used for 15-17-year-old subjects who were unaccompanied, seeking medical care associated with STI, and gave permission to contact their parent or legal guardian who then gave verbal permission over the phone to proceed with the study. Eighteen-year-old subjects could consent for themselves, but without their parents could provide only limited socioeconomic data about their family. Consent was obtained to review the medical record to determine history or current diagnosis of an STI or pregnancy.

\section{Study population}

Cases were African American adolescents seeking care at the Children's Hospital of Richmond and were 13-18 years of age with a diagnosis or history of STI or pregnancy. Controls were sexually inactive and matched 1:1 with cases for age in years (average age difference between cases and controls was 5 months), race, and gender, and were enrolled from the same clinic while seeking medical treatment unrelated to an STI or infection with an STI pathogen, such as herpes simplex. After obtaining consent, legal guardians completed a questionnaire that included information about parental education, medical insurance, family income, and age and number of siblings living in same household as the subject. Adolescents completed a separate questionnaire regarding sexual history, including current sexual activity, last sexual activity, first sexual activity, number of sexual partners, condom use, birth control use, history of STI and age of infection, prior or current pregnancies, and previous human immunodeficiency virus (HIV) testing. Subjects were recruited between 2010 and 2012 .

\section{Laboratory methods}

After giving their assent, the adolescent subjects provided saliva samples by expectoration into collection tubes. Saliva was stored at $-20^{\circ} \mathrm{C}$. The serologic CMV status of subjects was determined using a salivary enzyme immunoassay to CMV gB antigen as previously described. ${ }^{12-14}$ The salivary assay detects $\mathrm{IgG}$ to $\mathrm{gB}$ when serum neutralizing titers to CMV are $\geq 1: 64$ in the serum. The saliva assay was validated in a previous CMV seroprevalence study where the rate of seropositivity was identical to that previously detected using sera from African Americans in Richmond., ${ }^{72}$

\section{Sample size calculations}

Based on prior studies, we assumed a CMV seroprevalence of $80 \%$ in sexually active adolescents. This $80 \%$ rate has previously been reported by us for African American adults and is what has previously been reported for African Americans throughout the USA. ${ }^{1,711,12}$ We also observed previously a $40 \%$ seropositivity rate for sexually inactive adolescents. ${ }^{12}$ A power analysis showed a sample size of 22 case-control pairs would have $85 \%$ power to detect a difference in proportions of $0.400(80 \%$ seropositivity versus $40 \%$ seropositivity) when the proportion of discordant pairs is expected to be 0.500 and the method of analysis is a McNemar's test of equality of paired proportions with a 0.050 two-sided significance level. We tested the null hypothesis, ie, that there was no difference in seropositivity rates between sexually active and sexually inactive subjects.

\section{Statistical analysis}

There were two groups of cases. Group 1 had a diagnosis and/or laboratory findings of syphilis, gonorrhea, chlamydia, herpes simplex virus, history of laboratory-diagnosed 
pregnancy, human papillomavirus, bacterial vaginosis, or nondiagnostic laboratory findings of STI, a self-reported STI, or a pregnant partner plus reported sexual activity. Group 2 was sexually active by self-report only but without any diagnostic or nonspecific laboratory results to serve as objective criteria of sexual activity. Group 2 was included as a comparator to group 1 and to add statistical power if needed.

$P$-values and odds ratios were calculated for characteristics including CMV serostatus, birth control use, and HIV testing between cases and matched controls using McNemar's test. Questionnaire responses were voluntary, so not all subjects provided complete responses. $P$-values for characteristics with incomplete responses (family income, medical insurance, parental education, and siblings at home) were calculated using Fisher's exact test.

\section{Results}

In total, 114 subjects were enrolled, and of these, 38 cases were matched with 38 controls. The characteristics of the cases and controls are listed in Tables 1 and 2.

For group 1, where cases had objective evidence of sexual activity, seven of $22(32 \%)$ were seropositive for

Table I Characteristics of cases and controls in group I*

\begin{tabular}{|c|c|c|c|c|}
\hline Characteristics & Cases (\%) & Controls (\%) & $P$-value & OR $(95 \% \mathrm{Cl})$ \\
\hline Subjects (n) & 22 & 22 & & \\
\hline CMV-seropositive (n) & $7(31.8)$ & $7(31.8)$ & 0.7518 & $1.000(0.230-4.345)$ \\
\hline Mean age (years $\pm S D)$ & $17.3 \pm 1.3$ & $16.8 \pm 1.3$ & 0.0118 & \\
\hline \multicolumn{5}{|l|}{ Gender } \\
\hline Males (n) & $4(18.2)$ & $4(18.2)$ & ND & \\
\hline Females (n) & I8 (8I.8) & I8 (8I.8) & ND & \\
\hline Currently sexually active (n) & 17 & 0 & ND & \\
\hline Last sexual activity (months $\pm S D$ ) & $3.2 \pm 6$ & - & ND & \\
\hline Age at first sexual activity, years (mean $\pm S D$ ) & $14.2 \pm 2$ & - & ND & \\
\hline \multicolumn{5}{|l|}{ Sexual partners (n) } \\
\hline$<1$ & 0 & - & ND & \\
\hline $1-2$ & 15 & - & ND & \\
\hline $3-4$ & 2 & - & ND & \\
\hline$>4$ & 3 & - & ND & \\
\hline \multicolumn{5}{|l|}{ Condom use } \\
\hline Never & 0 & - & ND & \\
\hline Sometimes & 9 & - & ND & \\
\hline Always & 11 & - & ND & \\
\hline Using birth control (n) & 14 & 6 & 0.0961 & $3.333(0.858-18.849)$ \\
\hline History of an STD (n) & 22 & 0 & ND & \\
\hline Age at first STD, years (mean \pm SD) & $16.8 \pm 1.6$ & - & ND & \\
\hline HIV tested (n) & 11 & I & 0.0094 & $11.000(1.599-473.475)$ \\
\hline Pregnant (n) & 3 & 0 & ND & \\
\hline \multicolumn{5}{|l|}{ Family income } \\
\hline$<\$ 20,000$ & 6 & 11 & 0.6868 & \\
\hline$\$ 20,000-\$ 40,000$ & 3 & 3 & 0.6618 & \\
\hline$\$ 40,000-\$ 60,000$ & 2 & 1 & 0.5487 & \\
\hline$\$ 60,000-\$ 80,000$ & 0 & $\mathrm{I}$ & 1.000 & \\
\hline Medical insurance & 12 & 18 & 1.000 & \\
\hline \multicolumn{5}{|l|}{ Parental education } \\
\hline$<$ High school & 0 & 1 & 1.000 & \\
\hline High school/GED & 11 & 9 & 0.045 & II (I.I-104) \\
\hline College & I & 8 & 0.0492 & $8.8(0.9-83)$ \\
\hline Siblings at home (n) & 5 & 2 & 0.2074 & \\
\hline Ages of siblings at home, years & 12 & 19 & 0.2074 & \\
\hline Siblings $<5$ & 1 & 1 & 1.000 & \\
\hline Siblings 5-12 & 5 & 1 & 0.3544 & \\
\hline Siblings $>12$ & 7 & 5 & 0.6424 & \\
\hline
\end{tabular}

Notes: *Sexual activity defined by either specific laboratory findings (syphilis, gonorrhea, chlamydia, herpes simplex virus, pregnancy) or nonspecific laboratory findings (human papilloma virus, bacterial vaginosis, self-reported sexually transmitted infection, pregnant partner) and reported sexual activity.

Abbreviations: $\mathrm{Cl}$, confidence interval; CMV, cytomegalovirus; OR, odds ratio; SD, standard deviation; GED, General Educational Development; HIV, human immunodeficiency virus; STD, sexually transmitted disease; ND, not done. 
Table 2 Characteristics of cases and controls in group 2*

\begin{tabular}{|c|c|c|c|c|}
\hline Characteristics & Cases (\%) & Controls (\%) & $P$-value & OR $(95 \% \mathrm{Cl})$ \\
\hline Total subjects $(\mathrm{n})$ & 16 & 16 & & \\
\hline CMV-seropositive (n) & $6(37.5)$ & $\mathrm{I}(6.3)$ & 0.0736 & 0.000 \\
\hline Age, years (mean $\pm S D)$ & $15.4 \pm 1.3$ & $15.3 \pm 1.4$ & 0.249 & \\
\hline \multicolumn{5}{|l|}{ Gender } \\
\hline Male (n) & $7(43.8)$ & $7(43.8)$ & ND & \\
\hline Female $(n)$ & $9(56.3)$ & $9(56.3)$ & ND & \\
\hline Currently sexually active (n) & $14(87.5)$ & & ND & \\
\hline Last sexual activity (months $\pm S D$ ) & $3.6 \pm 3.9$ & - & ND & \\
\hline Age of first sexual activity, years (mean $\pm S D$ ) & $13.8 \pm 1.8$ & - & ND & \\
\hline \multicolumn{5}{|l|}{ Sexual partners $(n)$} \\
\hline$<1$ & 0 & - & ND & \\
\hline $\mathrm{I}-2$ & 11 & - & ND & \\
\hline $3-4$ & 2 & - & ND & \\
\hline$>4$ & 3 & - & ND & \\
\hline \multicolumn{5}{|l|}{ Condom use } \\
\hline Never & 0 & - & ND & \\
\hline Sometimes & 3 & - & ND & \\
\hline Always & 13 & - & ND & \\
\hline Using birth control (n) & 8 & 3 & 1.000 & $0.500(0.008-9.605)$ \\
\hline History of an STD (n) & 0 & 0 & ND & \\
\hline Age at first STD, years (mean \pm SD) & 6 & 1 & 0.1306 & $6.000(0.728-275.986)$ \\
\hline HIV tested (n) & 0 & 0 & ND & \\
\hline \multicolumn{5}{|l|}{ Pregnant (n) } \\
\hline Family income & 5 & 8 & 1.000 & \\
\hline$<\$ 20,000$ & 2 & 5 & 1.000 & \\
\hline$\$ 20,000-\$ 40,000$ & I & 0 & 0.3478 & \\
\hline$\$ 40,000-\$ 60,000$ & 0 & 2 & 0.5257 & \\
\hline$\$ 60,000-\$ 80,000$ & 12 & 14 & 1.000 & \\
\hline \multicolumn{5}{|l|}{ Medical insurance } \\
\hline Parental education & I & I & 1.000 & \\
\hline$<$ High school & 8 & 10 & 1.000 & \\
\hline High school/GED & 2 & 4 & 1.000 & \\
\hline College & I & 6 & 0.0809 & \\
\hline Siblings at home $(n)$ & 11 & 8 & 0.0809 & \\
\hline Ages of siblings at home & 2 & I & 1.000 & \\
\hline Siblings $<5$ years & 3 & 3 & 1.000 & \\
\hline Siblings $5-12$ years & 6 & 4 & 1.000 & \\
\hline
\end{tabular}

Note: *Sexual activity defined by report of sexual activity only.

Abbreviations: Cl, confidence interval; CMV, cytomegalovirus; OR, odds ratio; SD, standard deviation; GED, General Educational Development; HIV, human immunodeficiency virus; STD, sexually transmitted disease; ND, not done.

CMV and seven of 22 controls were also positive. In group 2, where cases self-reported sexual activity, six of $16(37.5 \%)$ cases were seropositive compared with one of $16(6.3 \%)$ controls $(P=0.07)$. The overall rate of seropositivity for all 38 cases was $34 \%$ (13 of 38) compared with a rate of $21 \%$ for all controls $(P=0.3$, odds ratio $2.0,95 \%$ confidence interval 0.6-7.5).

For group 1, the mean age of cases was $17.3 \pm 1.3$ years and that of controls was $16.8 \pm 1.3$ years. Use of birth control, family income, having medical insurance, and number of siblings were not significantly different from controls (Table 1). Cases were more likely to have been tested for HIV and the parents of controls were more likely to have attended college (Table 1).
For group 2, the mean age of cases was $15.4 \pm 1.3$ years and that of controls was $15.3 \pm 1.4$ years. Use of birth control, having been HIV-tested, family income, having medical insurance, parental education, and number of siblings in the household was similar between cases and controls (Table 2).

\section{Discussion}

African American adolescents have been reported by others to have CMV seroprevalence rates of $46 \%-89 \%{ }^{1-12}$ While true in the past, our data from this study and a previous one (a longitudinal study across all age groups of African Americans) suggest that the current generation of African American adolescents have CMV infection rates of 
only $22 \%-33 \%$, which is less than half the $70 \%$ rate for their parents and caregivers. ${ }^{12}$ In our previous study, we compared the socioeconomic characteristics of the African Americans in our Richmond study with those local, state-wide, and national rates and found them to be nearly identical. ${ }^{12}$ This, plus the association reported elsewhere between CMV infection and sexual activity suggested to us that a decrease in sexual activity among African American adolescents may be associated with a decrease in risk of CMV infection. Further, in our previous study, sexual activity was self-reported and there were no objective criteria for assessing sexual activity among subjects in that study. ${ }^{12}$ Therefore, in the present study, we focused on adolescents with objective and selfreported sexually activity and asked if this was associated with seroprevalence for CMV. It was not.

Our relatively small sample size was not a limitation. Our study was powered correctly using the estimates of seroprevalence we had previously observed using both serum-based and saliva-based assays. We tested the null hypothesis that there was no difference in seropositivity rates between sexually active and inactive subjects. We proved this hypothesis with an unequivocal result. With $85 \%$ statistical power, a larger sample size would not have changed this result. Enrolling further subjects could have confounded the results solely by chance.

$\mathrm{CMV}$ is present in most secretions, including saliva, urine, breast milk, cervical fluids, and semen. While oralmucosal transmission via saliva, urine, and breast milk are well documented, venereal transmission, while a reasonable hypothesis, has never been proven. A population-based study in the US conducted from 1988 to 1994 found an association between sexual activity and CMV seroprevalence, particularly in African Americans. ${ }^{1}$ Another study from the 1980s reported that CMV seropositivity was associated with number of recent sex partners among women attending an STD clinic. ${ }^{3}$ In 1992, an association between sexual activity and CMV seropositivity among adolescent females was also reported. ${ }^{6}$

However, in a more recent study of 1,585 females aged 12-17 years and enrolled between 2006 and 2010, sexual activity was not an independent predictor of the presence of CMV antibody. ${ }^{4}$ In that study, being African American and household contact with a young child were the only independent predictors of CMV infection. Our study was also unable to demonstrate an association between sexual activity and CMV seroprevalence. Therefore, we could not attribute the lower CMV infection rate we had previously observed in African American adolescents to sexual activity.
The importance of our observation is related to the fact that among women of child-bearing age between $40 \%$ and $80 \%$ are susceptible (seronegative) to CMV at conception. In the USA, the rate of susceptibility has been lowest $(<20 \%)$ among African Americans and Hispanics. A primary maternal infection with CMV in early pregnancy causes the majority of congenital disease. ${ }^{15-17}$ Immunity induced by wild-type CMV infection affords women a high degree of protection against acquisition of a second CMV infection and protects the fetus from severe postnatal sensorineural deafness and neurologic damage. In nearly every epidemiologic study where measured, contact with a young child younger than 3 years of age is the most important independent predictor for acquisition of CMV. ${ }^{2,49}$ This includes maternal acquisition of CMV during pregnancy and congenital infection. ${ }^{2,18}$ Unfortunately, most studies reporting an association between CMV infection and sexual activity have not included contact with a young child in the home as an independent variable. ${ }^{1,5,6,8,10,11}$ Two studies have included both contact with young children and sexual activity as potential risk factors for CMV infection. ${ }^{2,4}$ After adjusting for contact with a young child, one study found sexual activity was an independent risk factor for CMV infection and the other did not. Thus, it is possible that $\mathrm{CMV}$ is infrequently transmitted via the venereal route, and the observed association between CMV infection and sexually activity was not casual but rather confounded by the failure of previous studies to control for other routes of horizontal transmission.

Contact with a young child is also a risk factor and predictor of fetal infection for those who are seronegative, young, poor, and predominantly African American. ${ }^{2,19}$ One study monitored CMV seroconversion among 1,906 seronegative women attending a fertility clinic. ${ }^{20}$ Seroconversion was associated with having contact with a child younger than 3 years of age and with seropositivity of the sex partner. Since CMV is transmitted by young children with equal frequency to household mothers and fathers, this observation is not informative about spouse-to-spouse CMV transmission or transmission via the vaginal mucosal route.

In conclusion, our results confirm lower rates of $\mathrm{CMV}$ infection among the current generation of African American adolescents in Richmond compared with their parents' generation, and also show that this lower rate is not explained by differences in sexual activity. The lower CMV infection rate may be due to reduced contact with young children or even a reduced frequency and duration of breast feeding among current adolescents compared with their parents. If our observations for Richmond reflect national trends, a large proportion 
of the next generation of African American women will be susceptible to a primary CMV infection during pregnancy. Knowledge of risk factors for CMV infection will help with prevention strategies and targeting appropriate ages for a CMV vaccine.

\section{Acknowledgment}

This work was supported in part by grants from the National Institutes of Health.

\section{Disclosure}

The authors report no conflicts of interest in this work.

\section{References}

1. Staras SA, Flanders WD, Dollard SC, Pass RF, McGowan JE Jr, Cannon MJ. Influence of sexual activity on cytomegalovirus seroprevalence in the United States, 1988-1994. Sex Transm Dis. 2008;35:472-479.

2. Fowler KB, Pass RF. Risk factors for congenital cytomegalovirus infection in the offspring of young women: exposure to young children and recent onset of sexual activity. Pediatrics. 2011;118:e286-e292.

3. Coonrod D, Collier AC, Ashley R, DeRouen T, Corey L. Cytomegalovirus infection in women attending a sexually transmitted disease clinic. J Infect Dis. 1990;162:46-51.

4. Stadler LP, Bernstein DI, Callahan ST, et al. Seroprevalence and risk factors for cytomegalovirus infections in adolescent females. J Pediatric Infect Dis Soc. 2012;2:7-14.

5. Stanberry LR, Rosenthal SL, Mills L, et al. Longitudinal risk of herpes simplex virus (HSV) type 1, HSV type 2, and cytomegalovirus infections among young adolescent girls. Clin Infect Dis. 2004;39:1433-1438.

6. Sohn YM, Oh MK, Balcarek KB, Cloud GA, Pass RF. Cytomegalovirus infection in sexually active adolescents. J Infect Dis. 1991;163: 460-663.

7. Adler SP. Cytomegalovirus and child day care. N Engl J Med. 1989;321: 1290-1296.

8. White NH, Yow MD, Demmler GJ, et al. Prevalence of cytomegalovirus antibody in subjects between the ages of 6 and 22 years. $J$ Infect Dis. 1989;159:1013-1017.
9. Walmus BF, Yow MD, Lester JW, Leeds L, Thompson PK, Woodward RM. Factors predictive of cytomegalovirus immune status in pregnant women. J Infect Dis. 1988;157:172-177.

10. Staras SA, Dollard SC, Radford KW, Flanders WD, Pass RF, Cannon MJ. Seroprevalence of cytomegalovirus infection in the United States, 1988-1994. Clin Infect Dis. 2006;43:1143-1151.

11. Bate SL, Dollard SC, Cannon MJ. Cytomegalovirus seroprevalence in the United States: The National Health and Nutrition Examination Surveys, 1988-2004. Clin Infect Dis. 2010;50:1439-1447.

12. Wilms IR, Best AM, Adler SP. Cytomegalovirus infections among African-Americans. BMC Infect Dis. 2008;8:107.

13. Wang JB, Adler SP, Hempfling S, et al. Mucosal antibodies to human cytomegalovirus glycoprotein B occur following both natural infection and immunization with human cytomegalovirus vaccines. J Infect Dis. 1996;174:387-392.

14. Wang JB, Adler SP. Salivary antibodies to cytomegalovirus (CMV) glycoprotein B accurately predict CMV infections among preschool children. J Clin Microbiol. 1996;34:2632-2634.

15. Adler SP. Congenital cytomegalovirus screening. Pediatr Infect Dis J. 2005;24:1105-1106.

16. Nigro G, Adler SP, La Torre R, Best AM; Congenital Cytomegalovirus Collaborating Group. Passive immunization during pregnancy for congenital cytomegalovirus infection. $N$ Engl J Med. 2005;353: $1350-1362$.

17. Bodéus M, Kabamba-Mukadi B, Zech F, Hubinont C, Bernard P, Goubau P. Human cytomegalovirus in utero transmission: follow-up of 524 maternal seroconversions. J Clin Virol. 2010;47:201-202.

18. Adler SP, Finney JW, Manganello AM, Best AM. Prevention of childto-mother transmission of cytomegalovirus among pregnant women. $J$ Pediatr. 2004;145:485-491.

19. Fowler KB, Stagno S, Pass RF. Maternal immunity and prevention of congenital cytomegalovirus infection. JAMA. 2003;289:1008-1011.

20. Francisse S, Revelard P, De Maertelaer V, Strebelle E, Englert Y, Liesnard C. Human cytomegalovirus seroprevalence and risk of seroconversion in a fertility clinic population. Obstet Gynecol. 2009;114:285-291.
Adolescent Health, Medicine and Therapeutics

\section{Publish your work in this journal}

Adolescent Health, Medicine and Therapeutics is an international, peer-reviewed, open access journal focusing on health, pathology, and treatment issues specific to the adolescent age group. All aspects of health maintenance, preventative measures and disease treatment interventions are addressed within the journal and practitioners from

\section{Dovepress}

all disciplines are invited to submit their work as well as healthcare researchers and patient support groups. The manuscript management system is completely online and includes a very quick and fair peerreview system. Visit http://www.dovepress.com/testimonials.php to read real quotes from published authors. 